\title{
ß-Naphthoflavone abolishes interrenal sensitivity to ACTH stimulation in rainbow trout
}

\author{
J M Wilson, M M Vijayan, C J Kennedy ${ }^{1}$, G K Iwama \\ and T W Moon ${ }^{2}$ \\ Canadian Bacterial Diseases Network, and Department of Animal Science, University of British Columbia, Vancouver, Canada, ${ }^{1}$ Department of Biological \\ Sciences, Simon Fraser University, Burnaby, Canada and ${ }^{2}$ Department of Biology, University of Ottawa, Ottawa, Canada \\ (Requests for offprints should be addressed to M M Vijayan, Department of Animal Science, 208-2357 Main Mall, University of British Columbia, Vancouver, \\ Canada V6T 1Z4)
}

\begin{abstract}
We report for the first time that $\beta$-naphthoflavone (BNF) abolishes ACTH stimulation of cortisol production in rainbow trout (Oncorhynchus mykiss). There was significantly higher hepatic cytochrome P450 content and ethoxyresorufin O-de-ethylase and uridine- $5^{\prime}$ diphosphoglucuronic acid transferase activities in BNFtreated fish than in sham-treated controls. BNF did not significantly effect either plasma turnover or tissue distribution of $\left[{ }^{3} \mathrm{H}\right]$ cortisol-derived radioactivity. Hepatic membrane fluidity and hepatocyte capacity for cortisol uptake were not altered by BNF as compared with the sham-treated fish. These results taken together suggest that BNF does not affect cortisol-clearance mechanisms in
\end{abstract}

trout. A 3 min handling disturbance period elicited a plasma cortisol response in the sham-treated fish; however, the response in the BNF-treated fish was muted and significantly lower than in the sham fish. This in vivo response corroborates the lack of interrenal sensitivity to $\mathrm{ACTH}$ in vitro in the BNF-treated fish, suggesting that BNF affects the ACTH pathway in trout. Our results suggest the possibility that cytochrome $\mathrm{P} 450$-inducing compounds may affect cortisol dynamics by decreasing interrenal responsiveness to ACTH stimulation in fish, thereby impairing the physiological responses that are necessary for the animal to cope with the stressor.

Journal of Endocrinology (1998) 157, 63-70

\section{Introduction}

Cortisol, the major corticosteroid in fish plasma (Idler \& Truscott 1972), has been shown to have several physiological actions in fish, including effects on intermediary metabolism (Vijayan et al. 1994a, 1996), osmoregulation (Wendelaar Bonga 1993, McCormick 1995) and immune function (Maule et al. 1987). These physiological responses associated with cortisol stimulation may play an important role in allowing the fish to cope with stressful situations (Vijayan et al. 1997a). Release of cortisol into the circulation is under the control of the hypothalamus-pituitaryinterrenal axis, and the final step involves the release of pituitary hormones (primarily adrenocorticotrophic hormone $(\mathrm{ACTH})$ ), which stimulates the interrenal tissue to release cortisol (Donaldson 1981). Although several other hormones have been shown to stimulate cortisol release from interrenal tissue, ACTH is the dominant secretagogue (Schreck et al. 1989, Arnold-Reed \& Balment 1991, Lamers et al. 1992, Kloas et al. 1994). Plasma concentrations of cortisol are dependent upon the amount of cortisol that is released compared with the amount that is cleared from the circulation. Any alteration in cortisol dynamics may therefore have an impact upon the amount of hormone that is available for normal physiological functions.

Removal of cortisol from the circulation is primarily by the liver where it is metabolized and eliminated in the bile (Kime 1978, Truscott 1979). A recent study suggested that the hepatic potential for cortisol clearance is enhanced in 3,3',4,4'-tetrachlorobiphenyl (TCBP)-treated rainbow trout, perhaps as the result of the induction of cytochrome P450 enzymes (P450) in the liver (Vijayan et al. 1997b). The P450 enzymes, while being important in xenobiotic metabolism and bioactivation processes, also play an important role in the catabolism of steroids (Stegeman 1993) by transforming lipophilic substrates, including steroids, to more water-soluble or conjugatable products (Addison 1984). Indeed, Förlin \& Haux (1985) have shown that xenobiotic induction of $\mathrm{P} 450$ results in increased biliary clearance of $17 \beta$-oestradiol in rainbow trout in vivo. However, very little is known about the effect of P450 inducers on cortisol production and clearance in fish. As cortisol is an important metabolic hormone in fish, any alteration in its dynamics associated with exposure to contaminants could have a significant impact on the ability of the animal to mount a physiological response, thereby attenuating the chances 
of coping with subsequent natural or anthropogenic stressors.

We therefore tested the hypothesis that P450 inducers alter cortisol dynamics in rainbow trout (Oncorhynchus mykiss). $\beta$-Naphthoflavone (BNF) was used, as studies have clearly established this compound to be a potent inducer of P450 in trout (Celander et al. 1993, Vijayan et al. 1997c). The specific objectives of this study include investigation of the impact of BNF exposure on (i) interrenal response to ACTH stimulation of cortisol production in vitro, (ii) in vivo plasma turnover and tissue distribution of $\left[{ }^{3} \mathrm{H}\right]$ cortisol, and (iii) hepatic membrane fluidity and in vitro hepatocyte cortisol uptake in trout. Furthermore, we subjected trout to handling disturbance for $3 \mathrm{~min}$ in order to examine whether BNF exposure modified plasma cortisol response to a physical stressor in vivo.

\section{Materials and Methods}

Animals

Rainbow trout were obtained from West Creek Fish Farm (Abottsford, BC, Canada) and maintained in running dechlorinated tap water at Simon Fraser University (Burnaby, BC, Canada) under natural light conditions. The holding temperature during the study was approximately $6{ }^{\circ} \mathrm{C}$ and the fish were acclimated for a month before the experiment. Mean fish mass for all experiments was $267 \pm 6 \mathrm{~g}$.

\section{Experimental procedures}

Rainbow trout were lightly anaesthetized (2phenoxyethanol; 1:10000; Syndel Lab, Richmond, BC, Canada) and injected intraperitoneally with vehicle alone (mulgofen EL-719 in 0.9\% saline; GAF Ltd, Manchester, $\mathrm{UK}$ ) or with vehicle plus BNF $(50 \mathrm{mg} / \mathrm{kg}$ body mass; Sigma, St Louis, MO, USA). All experiments were carried out 3 days after injection, as previous studies have shown maximal P450 induction at this time (Celander et al. 1993, Vijayan et al. 1997c).

In vitro cortisol release Groups of six BNF- or shamtreated trout were killed by an overdose of buffered anaesthetic (1:5000; MS-222; Syndel, BC, Canada) and the fish bled by caudal puncture using a heparinized syringe. The plasma separated after centrifugation was stored frozen at $-70{ }^{\circ} \mathrm{C}$ for later cortisol measurement. The livers were quickly dissected and frozen between blocks of dry ice and stored at $-70{ }^{\circ} \mathrm{C}$ for determination of hepatic enzyme activity (see below). Head kidney (containing the interrenal tissue) from each fish was excised immediately and rinsed in ice-cold modified
Hanks buffer (Moon et al. 1985) and finely minced to approximately $1 \mathrm{~mm}^{3}$ in size as described by Vijayan \& Leatherland (1990). The tissue per fish was divided between six wells $(50 \mathrm{mg}$ tissue per well; 24-multiwell tissue culture plate; Falcon; Becton Dickinson Labware, Franklin Lakes, NJ, USA) and kept on ice in the dark, with periodic shaking during the experiment. Tissue pieces were preincubated at $4{ }^{\circ} \mathrm{C}$ for $1 \mathrm{~h}$ in $2 \mathrm{ml}$ buffer (stabilization period), and thereafter the supernatant was discarded and replaced with fresh buffer $(1 \mathrm{ml})$. After a $1 \mathrm{~h}$ control incubation period, the buffer was removed and frozen for later determination of cortisol concentration. A sample well (in duplicate) for each fish was then incubated with ACTH at $0,0 \cdot 01,0 \cdot 05,0 \cdot 10,0 \cdot 50$ or $1 \cdot 00 \mathrm{mU} /$ $\mathrm{ml}$ buffer (porcine ACTH; Sigma) for an hour. The supernatant was frozen (as above) and the tissue wet weight determined for each well. Control cortisol release (before the addition of $\mathrm{ACTH}$ ) was expressed as ng/h per mg wet weight. To overcome the differences in basal cortisol-release rates between tissue preparations (due to the heterogeneous distribution of interrenal tissue in head kidney), ACTH-stimulated cortisol release was expressed as percentage change over basal release, and corrected for the declining cortisol release with time as described by Arnold-Reed \& Balment (1994).

Plasma cortisol turnover rate Trout were fitted with a dorsal aortic cannula by the method of Sovio et al. (1975) and then given intraperitoneal injections of either vehicle or BNF immediately after cannulation. Three days later either BNF- $(n=7)$ or vehicle- $(n=6)$ injected fish were given a bolus injection of $5 \mu \mathrm{Ci}\left[{ }^{3} \mathrm{H}\right]$ cortisol (specific activity $78.4 \mathrm{Ci} / \mathrm{mmol}$; Amersham, Oakville, ON, Canada). Blood samples (100 $\mu \mathrm{l})$ were taken $0,2,4,6,8$, $10,15,30,60$ and $120 \mathrm{~min}$ after the injection of radiolabelled hormone. Injection and blood sampling were carried out via the dorsal aortic cannula. Plasma was separated by centrifugation and frozen for later analysis of cortisol concentration (see below). Total plasma ${ }^{3} \mathrm{H}$ radioactivity was determined in $25 \mu \mathrm{l}$ plasma samples using $10 \mathrm{ml}$ organic counting scintillant (OCS; Amersham), and analysed using a Beckman LS 6500 (Toronto, ON, Canada) with external quench correction.

Plasma clearance kinetics of $\left.{ }^{3} \mathrm{H}\right]$ cortisol were determined by regression analysis of a plot of specific activity $(\mathrm{dpm} / \mathrm{ng}$ cortisol) against time. The data were analysed by the method of 'curve peeling' (Shipley \& Clark 1972). The general equation for regression was:

$$
C=A \mathrm{e}^{-\alpha t}+B \mathrm{e}^{-\beta t}
$$

where $C$ is the injected dose at time $t, \beta$ and $B$ describe the respective slope and intercept of the slow component and $\alpha$ and $A$ are the respective slope and intercept of the fast component of radioactive decay. The turnover rate was calculated from these slopes and intercepts (Higgs \& Eales 
1976) and was expressed as $\mathrm{ng} / \mathrm{min}$ per $\mathrm{kg}$. Calculations were performed using SigmaPlot (Jandel Scientific, San Rafael, CA, USA).

It has been shown previously in salmonids using the bolus injection of $\left[{ }^{3} \mathrm{H}\right]$ cortisol that, at $4 \mathrm{~h}$ after the injection, $90 \%$ of the ${ }^{3} \mathrm{H}$ in the plasma is accounted for by cortisol $(\sim 60 \%)$ and cortisone $(\sim 30 \%)$ (Patino et al. 1985). In our experiment, the fast component of radioactivity decay occurred within $10 \mathrm{~min}$ and hence it is likely that most of the ${ }^{3} \mathrm{H}$ is accounted for by cortisol. However, it is possible that $\left[{ }^{3} \mathrm{H}\right]$ cortisone contributed in part to the slow component, and hence our results represent corticosteroid turnover rate.

Tissue distribution After the final blood sample had been taken, fish were killed by a blow to the head, and gill, posterior kidney, liver, muscle and gall bladder (bile) samples were collected and frozen for later determination of tissue $\left[{ }^{3} \mathrm{H}\right]$ cortisol distribution. Tissues were homogenized with a Teflon pestle and glass mortar in saline $(0.9 \%$ $\mathrm{NaCl}$ ), oxidized (45\% burn efficiency; OX-300, R J Harvey Instrument Corp, Hillsdale, NJ, USA), and bubbled through OCS; total ${ }^{3} \mathrm{H}$ was counted as above. Data are presented as d.p.m./mg wet weight, percentage of total dose, and as a proportion of radioactivity present in plasma (tissue:plasma ratio $=$ d.p.m. in tissue/d.p.m. in plasma). Bile samples were counted in the same manner as for plasma (above) and expressed as d.p.m./ml.

Hepatocyte cortisol uptake Hepatocytes were isolated from the livers of non-cannulated trout (four BNF-treated and five sham controls) by the protocol of Vijayan et al. (1994b). Cortisol uptake by isolated hepatocytes was measured as described by Vijayan et al. (1997b). Briefly, hepatocytes were incubated at $4{ }^{\circ} \mathrm{C}$ with $5 \mathrm{nM}\left[{ }^{3} \mathrm{H}\right]$ cortisol $(78.4 \mathrm{Ci} / \mathrm{mmol})$ and the incubation terminated by the addition of excess ice-cold phosphate buffer at $0,10,20$, $30,40,60,120$ and $300 \mathrm{~s}$ after the addition of radiolabelled cortisol. The rate of cortisol uptake was measured from the initial linear phase of the $(0-30 \mathrm{~s})$ slope and expressed as $\mathrm{pmol} / \mathrm{s}$ per mg wet weight.

Hepatic membrane fluidity Hepatic membrane fluidity was determined in purified plasma membrane preparations by the method of Sulakhe (1987). Membrane fluidity was measured by the fluorescence depolarization method of Crockett \& Hazel (1995) using the fluorescent probe 1,6-diphenyl-1,3,5-hexatriene. A PerkinElmer LS-50B luminescence spectrometer monitored fluorescence with excitation and emission monochrometers set at $356 \mathrm{~nm}$ and $430 \mathrm{~nm}$ respectively.

In vivo plasma cortisol response to stress Thirteen rainbow trout were cannulated as described above and were given intraperitoneal injections of vehicle (seven fish) or BNF (six fish) as described above. The fish were allowed to recover for 3 days and then subjected to handling disturbance involving netting and removal from the black box for $3 \mathrm{~min}$. Blood samples $(100 \mu \mathrm{l})$ were taken at 0 (prestress), $0.5,1,2,4,8$ and $24 \mathrm{~h}$ after handling, centrifuged and the plasma fraction frozen for the determination of cortisol concentration.

\section{Plasma cortisol concentration and hepatic enzyme activity}

Plasma cortisol concentration $(25 \mu \mathrm{l})$ was measured using a commercially available ${ }^{125}$ I-cortisol RIA kit (Diagnostic Products Corp, Los Angeles, CA, USA). The interand intra-assay coefficients of variation were less than 6\%. Hepatic microsomal total P450 content and ethoxyresorufin O-de-ethylase (EROD) and uridine-5'diphosphoglucuronic acid transferase (UDPGT) activity were measured as described by Omura \& Sato (1964), Burke \& Mayer (1974) and Kennedy et al. (1991) respectively.

\section{Statistical analysis}

Data are presented as means \pm s.E.M. The plasma cortisol response after stress and the in vitro cortisol release in response to ACTH stimulation were compared using two-way ANOVA. Where $P$ indicated significance $(<0 \cdot 05)$, means were compared using the post hoc StudentNewman-Keuls multiple comparison test. All other data were subjected to an unpaired $t$-test. Some data required $\log$ transformation in order to meet the assumption of homogeneity of variance, although non-transformed data are shown in the tables and figures.

\section{Results}

BNF treatment resulted in significantly higher hepatic EROD ( $~ 8$ fold), total P450 and UDPGT activities $(\sim 3$-fold) at 3 days when compared with the sham group (Table 1). There was no significant effect of BNF on plasma cortisol concentration when compared with the sham group in either the resting (non-cannulated) or cannulated trout (turnover study and in vivo stress response study) (Table 1); cannulation resulted in significantly higher plasma cortisol concentration in both the sham and BNF groups compared with the corresponding resting fish (Table 1).

The in vitro basal cortisol release rates from the interrenal preparations were not significantly different between the BNF-treated $(0.97 \pm 0.15 \mathrm{pmol} / \mathrm{h}$ per $\mathrm{mg}$ wet wt; $n=6$ fish) and sham-treated fish $(0.79 \pm 0.11 \mathrm{pmol} / \mathrm{h}$ per $\mathrm{mg}$ wet wt; $n=6$ fish). The interrenal tissue preparation from sham-treated fish showed a clear ACTH dose-response; the response plateaued at $0.5 \mathrm{mU} / \mathrm{ml}$ with no further increase at the higher dose of $1.0 \mathrm{mU} / \mathrm{ml} \mathrm{ACTH}$. This ACTH stimulation of cortisol secretion was completely abolished in the BNF-treated fish (Fig. 1). The disappearance of $\left[{ }^{3} \mathrm{H}\right]$ cortisol from the plasma was exponential 
Table 1 Effect of BNF on plasma cortisol concentrations (resting (uncannulated) and 3 day cannulated fish), plasma cortisol turnover rate and hepatic microsomal total P450 content, EROD and UDPGT activities in rainbow trout. Values represent means \pm S.E.M. $(n=6-7)$

Plasma cortisol (ng/ml)
Resting fish
Cannulated fish
Corticosteroid turnover rate $(\mathrm{ng} / \mathrm{kg}$ per min)
Total P450 ( $\mathrm{nmol} / \mathrm{mg}$ protein)
EROD $(\mathrm{pmol} / \mathrm{min}$ per $\mathrm{mg}$ protein)
UDPGT $(\mathrm{pmol} / \mathrm{min}$ per mg protein)

\section{Sham}

$\begin{aligned} 46 & \pm 15 \\ 81 & \pm 18 \\ 102 & \pm 32 \\ 0 \cdot 10 & \pm 0 \cdot 02 \\ 14 \cdot 11 & \pm 2 \cdot 28 \\ 0 \cdot 13 & \pm 0 \cdot 02\end{aligned}$

BNF

$$
\begin{aligned}
44 & \pm 7 \\
90 & \pm 23 \\
144 & \pm 42 \\
0 \cdot 33 & \pm 0 \cdot 07^{*} \\
120 \cdot 37 & \pm 13 \cdot 92^{*} \\
0 \cdot 31 & \pm 0 \cdot 03^{*}
\end{aligned}
$$

*Significantly different from the sham fish $(P<0 \cdot 05$, unpaired $t$-test); cannulated fish had significantly higher plasma cortisol concentrations than resting fish.

(Fig. 2), and there were no significant differences in $\left[{ }^{3} \mathrm{H}\right]$ cortisol turnover rate between the sham- and BNFtreated fish (Table 1); plasma cortisol concentrations remained constant over the course of the turnover study (Fig. 2, inset). There were no significant differences in the distribution of ${ }^{3} \mathrm{H}$ radioactivity between the sham- and BNF-treated groups in any of the tissues measured (Table 2 ). Cortisol-derived radioactivity was preferentially distributed to the liver and muscle at approximately 30 and $45 \%$ of the total dose respectively, whereas the other tissues (kidney and gill) sampled contained $2-5 \%$ of the isotope (Table 2). The ${ }^{3} \mathrm{H}$ radioactivity in the bile was approximately double that found in the liver (based on an equivalent volume:weight ratio). Unfortunately the volume of bile was not measured at the time of sampling and hence the activity relative to the total dose could not be expressed. The tissue to plasma ratio of $\left[{ }^{3} \mathrm{H}\right]$ cortisol in the liver was higher than in other tissues (Table 2).

The uptake of $\left[{ }^{3} \mathrm{H}\right]$ cortisol by trout hepatocytes showed an initial rapid phase (0 to $30 \mathrm{~s}$ ) followed by a slower phase (40 to $300 \mathrm{~s}$ ), and the uptake rate was not significantly different $(0$ to $30 \mathrm{~s}$ : sham, $3.1 \pm 0.7 \mathrm{pmol} / \mathrm{s}$ per $\mathrm{mg}$ wet wt; BNF, $3.7 \pm 0.6 \mathrm{pmol} / \mathrm{s}$ per mg wet wt) between the two groups (Fig. 3). The hepatocyte membrane order, as indicated by the 1,6-diphenyl-1,3,5-hexatriene fluorescence depolarization, was not significantly different between the two groups (data not shown).

A 3 min handling period resulted in a significant treatment (sham vs BNF) and time effect on plasma cortisol concentration. There was a significantly higher plasma cortisol concentration, regardless of the treatment, at $0 \cdot 5,1,2$ and $4 \mathrm{~h}$ after stress thereafter decreasing to prestress levels (Fig. 4, two-way ANOVA). However, the plasma cortisol concentration was significantly lower in the BNF-treated group compared with the sham-treated group (Fig. 4, two-way ANOVA).

\section{Discussion}

We report for the first time that BNF, a potent inducer of $\mathrm{P} 450$, affects the pituitary-interrenal axis in rainbow trout.
Specifically, BNF abolishes interrenal sensitivity to ACTH stimulation of cortisol production in vitro. This absence of a response to ACTH may be due to the effect of BNF on either ACTH receptor dynamics and/or the steroidogenic pathway in trout interrenal tissue. The absence of ACTHstimulated cortisol production has been shown previously in the interrenal tissue of tilapia treated with the organochlorine insecticide 1,1-dichloro-2,2-(o-chlorophenyl)-2-( $p$ chlorophenyl)ethane (o,p-DDD) (Ilan \& Yaron 1980). This suppressive effect of the insecticide, however, was abolished in the presence of $N^{6}, O^{2^{\prime}}$-dibutyryl cAMP. As cAMP is a major second messenger for ACTH stimulation in fish, these results suggest that the contaminant effect on the pituitaryinterrenal axis may be attributed to ACTH receptor downregulation and/or desensitization (Ilan \& Yaron 1980).

Recent studies have raised the possibility that P450 inducers may also affect the steroidogenic enzyme pathway of cortisol production. For example, in mice, the adrenotoxic environmental pollutant 3-methylsulphonyl2,2-bis-(4-chlorophenyl)-1,1-dichloroethene $\quad\left(\mathrm{MeSO}_{2}-\right.$ DDE, a metabolite of the insecticide DDT) decreased plasma corticosterone levels in mice (Jönsson 1994). This decrease was mediated by the bioactivation of $\mathrm{MeSO}_{2}-$ DDE by adrenal cytochrome P450c11 (a key mitochondrial enzyme involved in cortisol synthesis), resulting in the inhibition of steroid hydroxylase, which is on the final pathway of corticosterone biosynthesis (Lund \& Lund 1995). As BNF is a potent inducer of P450s in fish tissues, including interrenals (Husøy et al. 1994), it is possible that substrate competition by xenobiotics in the steroid biosynthetic pathway may result in lower cortisol production. Plasma cortisol concentration was higher in the cannulated fish than in the resting (uncannulated) fish regardless of BNF treatment (Table 1). As cannulation has been shown to be stressful and result in higher plasma cortisol levels in trout (Gamperl et al. 1994), the absence of any difference in elevated plasma cortisol levels between the sham- and BNF-treated fish argues against the possibility that BNF affects the corticosteroid biosynthetic pathway. Consequently, our results favour the hypothesis that the abolition of interrenal sensitivity to ACTH stimulation in BNFinjected trout is due to receptor downregulation and/or 


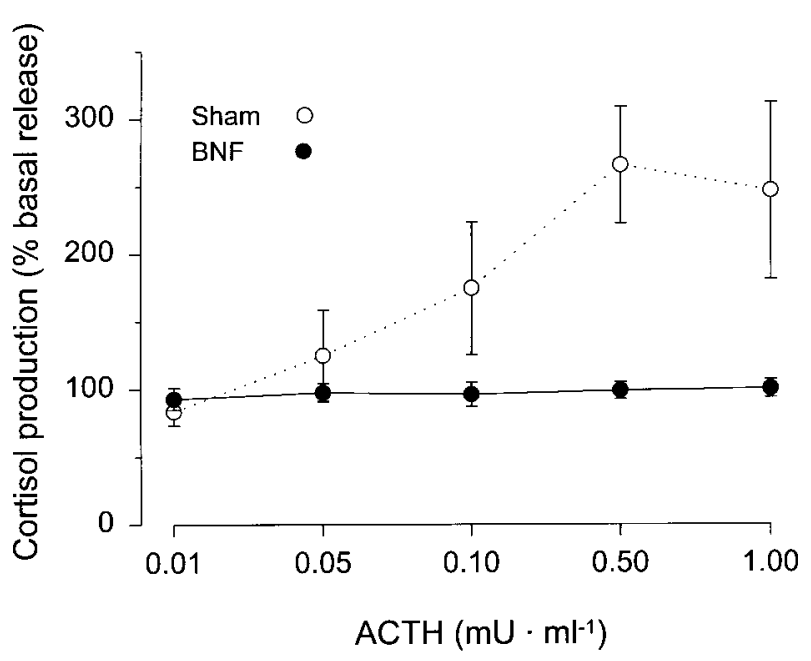

Figure 1 Interrenal cortisol release (\% basal release) in response to $\mathrm{ACTH}$ stimulation in vitro in sham and BNF-injected trout. Values represent means \pm S.E.M. $(n=6)$. Two-way ANOVA indicated a significant treatment effect (sham vs BNF) on cortisol production, which was significantly lower in BNF-injected fish than in the sham fish $(P<0 \cdot 05)$.

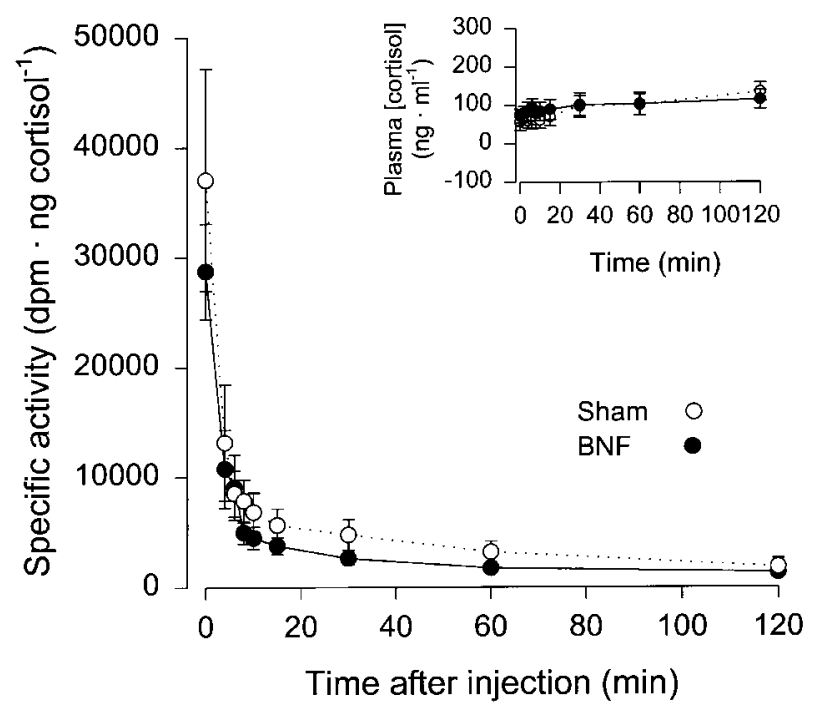

Figure 2 Time course of plasma specific activity decay after injection of $5 \mu \mathrm{Ci}\left[{ }^{3} \mathrm{H}\right]$ cortisol in sham and BNF-injected trout. Values represent means \pm S.E.M. $(n=6-7)$. The inset shows plasma cortisol concentrations $(\mathrm{ng} / \mathrm{ml})$ over the course of the experiment.

desensitization, as proposed earlier for tilapia exposed to $o, p$-DDD (Ilan \& Yaron 1980).

The absence of a difference in plasma cortisol concentration after BNF injection, despite the abolition of interrenal sensitivity to ACTH, suggests the possibility that BNF affects the plasma clearance rate of cortisol in fish. Studies have shown that BNF enhanced biliary elimination of $17 \beta$-oestradiol in trout (Förlin \& Haux 1985). As this contaminant induces hepatic P450 enzymes, these authors proposed that the P450 induction may enhance elimination of steroid, thereby making it unavailable for tissue physiology. Our study, however, showed that BNF had no significant effect on the corticosteroid-clearance mechanism (Fig. 2). Furthermore, BNF had no significant effect on the tissue distribution of cortisol-derived radioactivity, although the higher percentage of ${ }^{3} \mathrm{H}$ radioactivity in the liver and bile of trout in the present study does support hepatobiliary excretion as the major route for cortisol elimination in fish (Truscott 1979, Vijayan \& Leatherland 1990). The absence of a response in plasma corticosteroid turnover rate to BNF may be due to the stimulation already of the corticosteroid-clearance mechanism associated with the stress of cannulation (Gamperl et al. 1994). However, a $3 \mathrm{~min}$ handling period in the cannulated sham group resulted in an immediate increase in plasma cortisol levels, followed by a fall to the prehandling levels (Fig. 4), suggesting that these fish still respond to the stress of handling. Also, the magnitude of cortisol response after stress in the cannulated fish to the handling disturbance was similar to that of uncannulated trout subjected to a similar stressor (Vijayan et al. 1994b, Vijayan et al. 1997c), thereby arguing against the possibility that the clearance mechanism is maximally stimulated in these cannulated fish. The BNF treatment, however, did affect the plasma cortisol response to a handling disturbance in the cannulated trout (present study) compared with the uncannulated trout (Vijayan et al. 1997c), suggesting the possibility that BNF treatment affects the ability of the fish to mount a cortisol response to an additional stressor.

There was a clear attenuation of this rise in plasma cortisol concentration with handling stress in the BNFtreated fish (Fig. 4). This in vivo plasma cortisol response to stress corroborates with the in vitro lack of cortisol production with ACTH stimulation in the BNF-treated fish (Figs 1 and 4). ACTH is the primary secretagogue for cortisol release with stress in fish, and consequently our results suggest the possibility that the BNF effect on the pituitary-interrenal axis is at the level of the ACTH receptors. As cortisol is involved in the regulation of physiological functions that adjust the animal to cope with stress, inhibition of the pituitary-interrenal axis will in turn impair the ability of the animal to cope with stressors (Vijayan et al. 1997a). In support of this argument, the plasma cortisol response to capture was absent in fish collected from heavily polluted areas (Hontela et al. 1992). These authors proposed that prolonged exposure to pollutants may lead to hyperactivity, and as a result in the exhaustion of the pituitary-interrenal axis as evidenced by the presence of atrophied pituitary corticotropes. Our results, however, support downregulation and/or desensitization of the ACTH receptors as an additional mechanism for the suppressed cortisol response to cope with stressors in these fish. 
Table 2 Effect of BNF on total (d.p.m./mg wet weight) and percentage tissue ${ }^{3} \mathrm{H}$ radioactivity (percentage of total dose), and as a proportion of radioactivity present in plasma (tissue:plasma ratio (T/P ratio) $=$ d.p.m./g tissue $/$ d.p.m. $/ \mathrm{ml}$ plasma) after injection of $\left[{ }^{3} \mathrm{H}\right]$ cortisol. Values represent means \pm S.E.M. $(n=6-7)$

\begin{tabular}{|c|c|c|c|c|c|}
\hline & Muscle & Liver & Kidney & Gill & Bile \\
\hline \multicolumn{6}{|c|}{ Tissue ${ }^{3} \mathrm{H}$ radioactivity } \\
\hline BNF & $32 \cdot 1 \pm 3 \cdot 5$ & $1020 \pm 125$ & $245 \pm 14$ & $91 \cdot 3 \pm 7 \cdot 8$ & $2 \cdot 53 \pm 0.90$ \\
\hline Sham & $37 \cdot 8 \pm 5 \cdot 2$ & $1103 \pm 108$ & $273 \pm 15$ & $91 \cdot 7 \pm 5 \cdot 6$ & $1 \cdot 78 \pm 0.56$ \\
\hline BNF & $39 \cdot 5 \pm 5 \cdot 3$ & $28 \cdot 3 \pm 3 \cdot 1$ & $4 \cdot 48 \pm 0 \cdot 22$ & $1 \cdot 94 \pm 0.11$ & na \\
\hline Sham & $47 \cdot 4 \pm 6 \cdot 6$ & $31 \cdot 9 \pm 3 \cdot 5$ & $5 \cdot 18 \pm 0 \cdot 37$ & $2 \cdot 02 \pm 0 \cdot 14$ & na \\
\hline \multicolumn{6}{|l|}{$\mathrm{T} / \mathrm{P}$ ratio } \\
\hline
\end{tabular}

Tissue radioactivity in bile expressed as $10^{6}$ d.p.m./ml. na, not applicable.

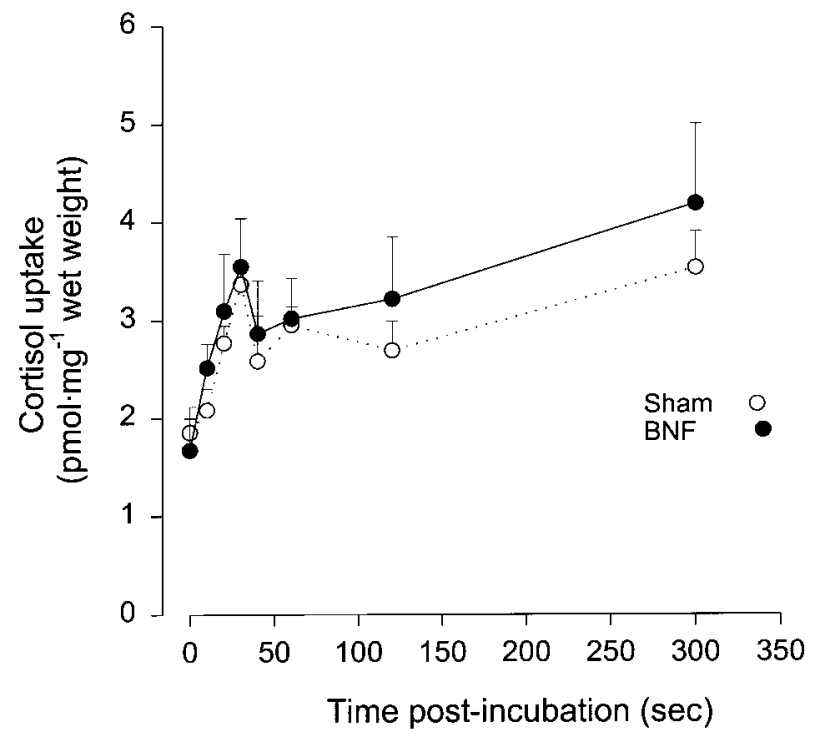

Figure 3 Time course of $\left[{ }^{3} \mathrm{H}\right]$ cortisol uptake into isolated hepatocytes in sham and BNF-injected trout. Values represent means \pm S.E.M. $(n=4-5)$; see Materials and Methods for the procedures.

We have shown previously that hepatocytes catabolize cortisol and that TCBP (a potent inducer of P450) enhanced the hepatocyte capacity for cortisol uptake and catabolism in trout (Vijayan et al. 1997b). In that study we proposed that the higher uptake of cortisol by hepatocytes with TCBP may be due to changes in the membrane order. In the present study, although there was a significant induction of mono-oxygenase (phase I) and conjugation (phase II) enzyme activities (Table 1), there was no effect of BNF on hepatocyte cortisol uptake (Fig. 3) or hepatocyte membrane order (data not shown), suggesting that the changes in hepatocyte cortisol dynamics may be contaminant specific. It is also possible that the differences in hepatocyte cortisol response between this study and the earlier one may be related to the duration of exposure; the TCBP-treated fish were given oil implants and sampled 6

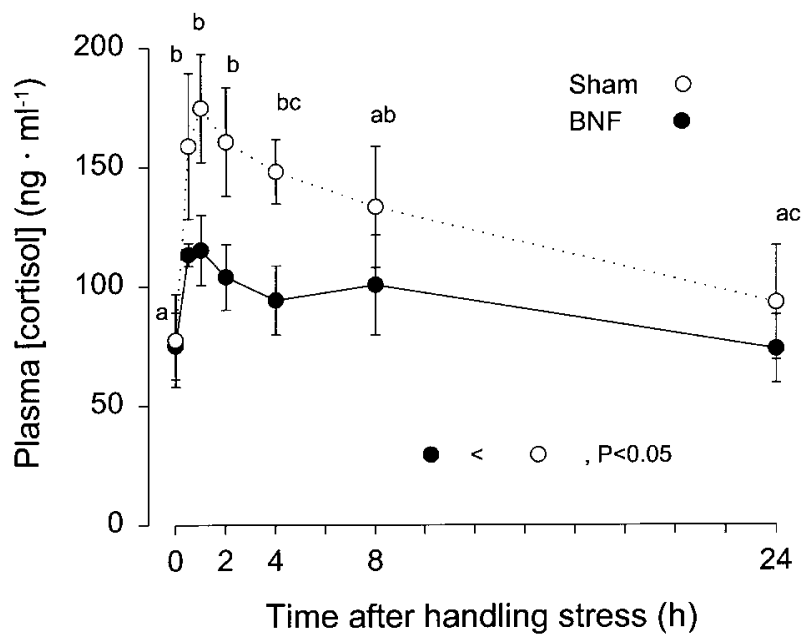

Figure 4 In vivo effect of a 3 min handling period on plasma cortisol concentration over time in sham and BNF-injected trout. Values represent means \pm S.E.M. $(n=6-7)$. Two-way ANOVA indicates a significantly lower plasma cortisol concentration after stress in the BNF-treated fish than in the sham fish $(P<0 \cdot 05)$; letters indicate a significant time effect, regardless of the treatment, and symbols with the same letters are not significantly different $(P<0 \cdot 05$, two-way ANOVA).

weeks later, whereas the BNF-treated fish were sampled 3 days after the injection. As both TCBP and BNF exposure results in the induction of phase I and phase II enzyme activities (see Celander et al. 1993, Otto \& Moon 1995, Vijayan et al. 1997b,c), the differences in plasma cortisol concentration and hepatocyte cortisol dynamics between the two contaminants raises the possibility that cortisol dynamics may be modulated by factors in addition to P450 activation. Further research is certainly warranted to understand the mechanism(s) of action of contaminants on cortisol dynamics in fish.

In conclusion, our results show that BNF abolishes interrenal sensitivity to ACTH in vitro, and also decreases the plasma cortisol response to handling stress in vivo in cannulated fish. BNF, however, did not affect either the 
resting plasma cortisol concentration or the cannulationinduced elevation of plasma cortisol level. This suggests that the effect of BNF on the pituitary-interrenal axis is at the level of the interrenal response to ACTH stimulation and not at the level of the corticosteroid biosynthetic pathway. Also, the maintenance of plasma cortisol concentration in the BNF-treated fish compared with the sham-treated fish is not due to changes in plasma clearance or tissue distribution of cortisol-derived radioactivity. As the interrenal sensitivity to ACTH is curtailed in the BNF-treated group, we hypothesize that other hormonal pathways, in addition to ACTH, may be playing a role in the maintenance of plasma cortisol concentration. As several pituitary and extrapituitary hormones stimulate cortisol release in fish (Schreck et al. 1989, Arnold-Reed \& Balment 1991, 1994, Lamers et al. 1992, Kloas et al. 1994), it is likely that these additional pathways take on prominence in the absence of ACTH stimulation. However, the muted cortisol response to acute handling stress in the BNF-treated group suggests that the ACTH pathway is key to the cortisol response to acute stress in fish. Our results suggest that contaminants that induce the $\mathrm{P} 450$ enzymes may affect the pituitary-interrenal axis in fish by abolishing the interrenal response to ACTH stimulation, thereby impairing the physiological responses that are necessary for the animal to cope with additional stressors.

\section{Acknowledgements}

Thanks are extended to Drs Cristina Pereira and Kurt Gamperl and Mr Kevin Smyth and Ms Anna Lemke for their help during various stages of this study. The study was supported by grants from the DFO/NSERC Science Subvention Program to T W M, an NSERC Industrial Fellowship to $\mathrm{M} \mathrm{MV}$, and an operating grant to G K I from the Canadian Bacterial Diseases Network. Membrane fluidity experiments were undertaken in the laboratory of Dr J Hazel, Arizona State University under the guidance of Dr L Crockett.

$\mathrm{J} \mathrm{M} \mathrm{W} \mathrm{and} \mathrm{M} \mathrm{M} \mathrm{V} \mathrm{contributed} \mathrm{equally} \mathrm{to} \mathrm{this} \mathrm{work.}$

\section{References}

Addison RF 1984 Hepatic mixed function oxidase (MFO) induction in fish as a possible biological monitoring system. In Advances in Environmental Science and Technology. Contaminant Effects on Fisheries, vol 16, pp 51-60. Eds VW Carns, PV Hodson \& JO Nriagu. New York: Wiley-Interscience.

Arnold-Reed DE \& Balment RJ 1991 Atrial natriuetic factor stimulates in vivo and in vitro secretion of cortisol in teleosts. Journal of Endocrinology 128 R17-R20.

Arnold-Reed DE \& Balment RJ 1994 Peptide hormones influence in vitro interrenal secretion of cortisol in the trout, Oncorhynchus mykiss. General and Comparative Endocrinology 96 85-91.

Burke MD \& Mayer RT 1974 Ethoxyresorufin: direct fluorometric assay of microsomal O-dealkylation which is preferentially induced by 3-methylcolanthrene. Drug Metabolism and Disposition 2 583-588.
Celander M, Leaver, MJ, George, SG \& Förlin L 1993 Induction of cytochrome P450 1A1 and conjugating enzymes in rainbow trout (Oncorhynchus mykiss) liver: a time course study. Comparative Biochemistry and Physiology 106C 343-349.

Crockett EL \& Hazel JR 1995 Chloesterol levels explain inverse compensation of membrane order in brush border but not homeoviscous adaptation in basolateral membranes from the intestinal epithelia of rainbow trout. Journal of Experimental Biology 198 1105-1113.

Donaldson EM 1981 The pituitary-interrenal axis as an indicator of stress in fish. In Stress and Fish, pp 11-47. Ed AD Pickering. London: Academic Press.

Förlin L \& Haux C 1985 Increased excretion in the bile of $17 \beta-\left[{ }^{3} \mathrm{H}\right]$ estradiol-derived radioactivity in rainbow trout treated with $\beta$-Naphthoflavone. Aquatic Toxicology 6 197-208.

Gamperl AK, Vijayan MM \& Boutilier RG 1994 Epinephrine, norepinephrine, and cortisol concentrations in cannulated seawater-acclimated rainbow trout (Oncorhynchus mykiss) following black-box confinement and epinephrine injection. Journal of Fish Biology 45 313-324.

Higgs DA \& Eales JG 1976 Influence of injection route on radiothyroxine kinetics in brook trout, Salvelinus fontinalis (Mitchill). Canadian Journal of Zoology 54 255-259.

Hontela A, Rasmussen JB, Audet C \& Chevalier G 1992 Impaired cortisol response in fish from environments polluted by $\mathrm{PAHs}$, PCBs and mercury. Archives of Environmental Contamination and Toxicology 22 278-283.

Husøy A-M, Myers MS, Willis ML, Collier TK, Celander M \& Goksöyr A 1994 Immunohistochemical localization of CYP1A and CYP3A-like isozymes in hepatic and extrahepatic tissues of Atlantic cod (Gadus morhua L.), a marine fish. Toxicology and Applied Pharmacology 129 294-308.

Idler DR \& Truscott B 1972 Corticosteroids in fish. In Steroids in Non-Mammalian Vertebrates, pp 127-252. Ed DR Idler. New York: Academic Press.

Ilan Z \& Yaron Z 1980 Suppresion by organochlorines of the response to adrenocorticotrophin of the interrenal tissue in Sarotherodon Aureus (Teleostei). Journal of Endocrinology 87 185-193.

Jönsson C-J 1994 Decreased plasma corticosterone levels in suckling mice follows injection of adrenal toxicant, $\mathrm{MeSO}_{2}-\mathrm{DDE}$, to the lactating dam. Pharmacology and Toxicology 74 58-60.

Kennedy CJ, Gill KA \& Walsh PJ 1991 Temperature acclimation of xenobiotic metabolizing enzymes in cultured hepatocytes and whole liver of the gulf toadfish, Opsanus beta. Canadian Journal of Fisheries and Aquatic Science 48 1212-1219.

Kime DE 1978 The hepatic catabolism of cortisol in teleost fish: adrenal origin of 11-oxotestosterone precursors. General and Comparative Endocrinology 35 322-328.

Kloas W, Reinecke M \& Hanke W 1994 Role of atrial natriuretic peptide for adrenal regulation in the teleost fish Cyprinus carpio. American Journal of Physiology 267 R1034-R1042.

Lamers AE, Flik G, Atsma W \& Wendelaar Bonga SE 1992 A role for di-acetyl $\alpha$-melanocyte-stimulating hormone in the control of cortisol release in the teleost Oreochromis mossambicus. Journal of Endocrinology 135 285-292.

Lund B-O \& Lund J 1995 Novel involvement of a mitochondrial steroid hydroxylase (P450c11) in xenobiotic metabolism. Journal of Biological Chemistry 270 20895-20897.

McCormick SD 1995 Hormonal control of gill $\mathrm{Na}^{+}, \mathrm{K}^{+}$-ATPase and chloride cell function. In Cellular and Molecular Approaches to Fish Ionic Regulation, pp 285-315. Eds CM Wood \& TJ Shuttleworth. New York: Academic Press.

Maule AG, Schreck CB \& Kaattari SL 1987 Changes in the immune system of coho salmon (Oncorhynchus kisutch) during the parr-to-smolt transformation and after implantation of cortisol. Canadian Journal of Fisheries and Aquatic Science 44 161-166. 
Moon TW, Walsh PJ \& Mommsen TP 1985 Fish hepatocytes: a model metabolic system. Canadian Journal of Fisheries and Aquatic Science 42 1772-1782.

Omura T \& Sato R 1964 The carbon monoxide binding pigment of liver microsomes. Journal of Biological Chemistry $2392370-2378$.

Otto DME \& Moon TW 1995 3,3',4,4'-Tetrachlorobiphenyl effects on antioxidant enzymes and GSH status in different tissues of rainbow trout. Pharmacology and Toxicology 77 281-287.

Patino R, Schreck CB \& Redding JM 1985 Clearance of plasma corticosteroids during smoltification of coho salmon, Oncorhynchus kisutch. Comparative Biochemistry and Physiology 82A 531-535.

Schreck CB, Bradford CS, Fitzpatrick MS \& Patino R 1989 Regulation of the interrenal tissue of fishes: non-classical control mechanisms. Fish Physiology and Biochemistry 7 259-265.

Shipley RA \& Clark RE 1972 Tracer Methods for In Vivo Kinetics: Theory and Applications. New York: Academic Press.

Sovio A, Nynolm K \& Westman K 1975 A technique for repeated sampling of the blood of individual resting fish. Journal of Experimental Biology 62 207-217.

Stegeman JJ 1993 The cytochromes P450 in fish. In Biochemistry and Molecular Biology of Fishes, vol 2, pp 137-158. Eds PW Hockachka \& TP Mommsen. Amsterdam: Elsevier Science Publishers.

Sulakhe SJ 1987 Hepatic adrenergic receptors in the genetically diabetic C57 BL/KsJ $(\mathrm{db} / \mathrm{db})$ mouse. International Journal of Biochemistry 19 1181-1186.

Truscott B 1979 Steroid metabolism in fish: identification of steroid moieties of hydrolyzable conjugates of cortisol in the bile of trout Salmo gairdnerii. General and Comparative Endocrinology 38 196-206.

Vijayan MM \& Leatherland JF 1990 High stocking density affects cortisol secretion and tissue distribution in brook char, Salvelinus fontinalis. Journal of Endocrinology 124 311-318.
Vijayan, MM, Reddy PK, Leatherland JF \& Moon TW 1994a The effects of cortisol on hepatocyte metabolism in rainbow trout: a study using the steroid analogue RU486. General and Comparative Endocrinology 96 75-84.

Vijayan MM, Pereira C \& Moon TW 1994b Hormonal stimulation of hepatocyte metabolism in rainbow trout following an acute handling stress. Comparative Biochemistry and Physiology 108C 321-329.

Vijayan MM, Mommsen TP, Glemet HC \& Moon TW 1996 Metabolic effects of cortisol treatment in a marine teleost, the sea raven. Journal of Experimental Biology 199 1509-1514.

Vijayan MM, Pereira C, Grau EG \& Iwama GK 1997a Metabolic responses associated with confinement stress in tilapia: the role of cortisol. Comparative Biochemistry and Physiology 116C 89-95.

Vijayan MM, Feist G, Otto DME, Schreck CB \& Moon TW $1997 b$ $3,3^{\prime}, 4,4^{\prime}$-Tetrachlorobiphenyl affects cortisol dynamics and hepatic function in rainbow trout. Aquatic Toxicology 37 87-98.

Vijayan MM, Pereira C, Forsyth RB, Kennedy CJ \& Iwama GK $1997 c$ Handling stress does not affect the expression of hepatic heat shock protein 70 and conjugation enzymes in rainbow trout treated with $\beta$-naphthoflavone. Life Sciences 61 117-127.

Wendelaar Bonga SE 1993 Endocrinology. In The Physiology of Fishes, pp 469-502. Ed DH Evans. Bocan Raton, Florida: CRC Press.

Received 4 April 1997

Revised manuscript received 28 July 1997

Accepted 27 October 1997 